\title{
The nanostructure of the cell wall of softwoods and its functions 003569 in a living tree
}

\author{
R. E. Booker, J. Sell
}

Trees are large engineering structures that have to withstand major wind and static forces and translocate considerable volumes of water. Natural selection has over millions of years optimised tree structure to maximise survival of the species. Naturally this process does not necessarily optimise the properties of the resultant lumber such as hardness, stiffness and strength. Such wood properties can now be improved by genetic engineering and tree breeding. If this is done without understanding the contribution of wood structure to tree survival, this can lead to increased susceptibility to windthrow, splitting and branch damage in the standing tree and internal checking and collapse during wood drying. As a first step to quantifying these potential problems this paper reviews latest findings on the nanostructure of the cell wall of softwoods and then discusses the probable relationships between microfibril directions in the secondary cell wall layers and potential threats to the survival of trees such as excessive vibration and crack propagation.

\section{Nanostruktur der Zellwand des Nadelholzes und ihre Funktion im lebenden Baum}

Bäume können als große Holzkonstruktionen aufgefaßt werden, die starken statischen und Windbelastungen ausgesetzt sind sowie große Mengen an Wasser transportieren. Die natürliche Selektion hat über Jahrmillionen die Holzstruktur und damit das Überleben der Arten optimiert. Dieser Prozess optimierte nicht notwendigerweise die resultierenden Eigenschaften von Schnittholz wie Härte, Steifheit und Festigkeit. Solche Holzeigenschaften können inzwischen durch Züchtung und genetische Manipulation verbessert werden. Werden diese Versuche unternommen, ohne die Bedeutung der Holzstruktur für das Überleben des Baumes zu kennen, so kann das zu verstärkter Anfälligkeit für Windbruch, Risse und Astschäden am stehenden Baum sowie zu Rißbildung und Kollaps während des Trocknens führen. Als ersten Schritt zur Quantifizierung dieser möglichen Probleme gibt diese Arbeit einen Überblick über jüngste Erkenntnisse zur Nanostruktur der Zellwand in Nadelholz. Daran anschließend erfolgt eine Diskussion wahrscheinlicher Beziehungen zwischen der Orientierung der Mikrofibrillen in den Sekundärwänden und möglichen Gefahren für das Überleben des Baumes wie übermäßige Vibrationen und Rißfortpflanzung.

R. E. Booker

New Zealand Forest Research Institute, Wood Processing

Division, Private Bag 3020, Rotorua, New Zealand

J. Sell

Swiss Federal Laboratories for Materials Testing and Research, Wood Dept, CH-8600, Dübendorf, Switzerland

Correspondence to: R. E. Booker
1

\section{Introduction}

1.1.

Importance of wood structure for tree survival and tree breeding

The general importance of wood structure for the functions of a tree - a masterpiece of evolutionary design - is quite obvious. This structure makes it possible for huge amounts of biomass to be supported by astonishingly slim stems to heights of sometimes more than 50 metres. Even large static and dynamic forces of gravity and wind-loads are usually accommodated without damage to the tree. Additionally, the same wood structure provides for remarkably efficient water transport from the roots to the crown without causing collapse of the wood cell walls by the high water tension necessary for this transport. With the increasing importance and possibilities of genetic engineering and tree breeding that can develop trees with improved wood properties such as increased density and decreased spiral grain, it is becoming imperative that the relationships between wood structure and tree survival are fully understood, to avoid breeding trees that have en hanced wood properties, but poor survival prospects. As a first step to quantifying these potential problems this paper discusses the nanostructure of the cell wall of softwoods and the relationships between microfibril directions in the secondary cell wall layers and potential threats to the survival of trees such as excessive vibration and crack propagation.

\section{2}

\section{Levels of wood structure}

At least four different levels of wood structure can be identified, requiring more and more sophisticated equipment for analysis as the size decreases:

1. Macroscopic structure, visible by the naked eye; of the order of millimetres or above. This includes large tissue elements such as growth rings.

2. Microscopic structure, visible by light and electron microscopy; of the order of micrometers. This includes cellular structure and dimensions and the main elements of the cell wall.

3. Nanostructure ("ultrastructure"), visible by electron microscopy and "indirect methods" like X-ray diffraction; of the order of nanometres. This includes the fine structure of the cell wall and fibril/matrix structure.

4. Molecular structure, visible by atomic force microscopy and indirect methods; of the order of tenths of nanometres.

All these structures are optimised with respect to the functions mentioned above. In this article we describe new 
findings on the nanostructure level and present a proposal the S3 layer microfibrils are oriented from about $60^{\circ}$ for a modified cell wall model and its functions.

2

\section{Anatomy of the cell wall}

\section{1}

\section{Microfibril orientation in cell wall layers}

The literature on the nanostructure of wood describes its cell wall as an arrangement of layers of different thicknesses that have different fractions of the main chemical compounds. Cellulose occurs mainly in the helically wound reinforcing fibrils while hemicellulose and lignin serve as a gluing and stiffening matrix. As an analogy, the cellulose microfibrils serve a function similar to the steel rods in reinforced concrete, while hemicellulose acts like the cement and lignin acts like the rock and sand filler. The two walls of adjacent softwood cells are connected by a compound middle lamella (CML), which consists mainly of lignin. The walls themselves, which are called secondary walls $(\mathrm{S})$, form subsequent to the primary wall $(\mathrm{P})$ in three distinct layers.

The most commonly accepted cell structure is shown in figure 1 (Harada and Côté, 1985). According to this model the thin $\mathrm{S} 1$ layer lies adjacent to the CML (thickness about 0.1 to $0.2 \mu \mathrm{m}$ ) and consists mainly of cellulosic lamellae in which the microfibril orientation is in alternating S-and Zhelices with large inclinations to the longitudinal cell axis. The inner S3 layer (thickness 0.1 to $0.2 \mu \mathrm{m}$ ) lies adjacent to the cell lumen and consists of a thin layer of microfibrils with a flat helix like the S1 layer. The central thick S2 layer (I to $5 \mu \mathrm{m}$ ) has a particularly high content of cellulose fibrils helically oriented with a typical $\mathrm{Z}$ inclination to the cell axis of 10 to $30^{\circ}$. Most investigators also identify transition lamellae S12 and S23 with microfibril orientations between those of the $S 1$ and $S 2$ and $S 2$ and S3 respectively. The fibrils of the $S 1$ and $S 3$ layers are more or less perpendicularly oriented to the fibrils in the S2 layer.

Recently Abe, Ohtani and Fukuzawa (1991) using field emission scanning electron microscopy investigated the orientation of the microfibrils of the cell wall in Abies sachalinensis Masters and modified this picture somewhat. They found that in the S1 layer the microfibril orientation changes stepwise in a counter-clockwise direction from the outside to the inside, from roughly $45^{\circ}$ in an S-helix in the outermost lamella to about $70^{\circ}$ in a Z-helix at the S12 boundary. In $\mathrm{S} 12$ the lamellae directions are intermediate between S1 and S2. The S2 layer consists of closely packed microfibrils at an angle between $0^{\circ}$ and $20^{\circ}$ in a Z-helix. In the innermost $S 3$ layer microfibril angles vary from $70^{\circ}$ in a Z-helix to about $30^{\circ}$ in an S-helix. However, the microfibril angle at the innermost S3 layer varies from tracheid to tracheid, and ranges from about $30^{\circ}$ in an S-helix to about $90^{\circ}$. In the S23 layer the angle ranges from 60 to $40^{\circ}$ in a Z-helix.

From a cell mechanical point of view it is sensible to combine the S12 and S1 layers and S23 and S3 layers, so that their results can be summarised as follows:

- There are effectively only three cell wall layers, S1, S2 and $\mathrm{S3}$

- In the S1 layer microfibrils change in orientation from one side to the other from $45^{\circ}$ in an $S$ helix through $90^{\circ}$ to about $70^{\circ} \mathrm{Z}$ on the other side. The microfibrils of the outside and inside layers of $S 1$ are essentially perpendicular, while most microfibrils lie more or less perpendicular to the cell axis.
$\mathrm{Z}$ on the outside to $30^{\circ} \mathrm{S}$ on the inside. Hence also in S3 the microfibrils of the outside and inside layers are essentially perpendicular, while most lie more or less perpendicular to the cell axis.

- In the S2 layer the microfibrils are closely packed, but not in the other two layers.

It should be stressed that the microfibril angles determined by Abe et al. (1991) for the S1, S2 and S3 layers are approximate only, as they clearly stated: "The boundaries between each layer (S1, S2 and S3) could not be determined distinctly, because the angle of the microfibrils shifted progressively from the outermost to the innermost lamellae in the secondary wall."

In addition, the patterns may vary somewhat between species, but it is highly unlikely that this will affect the simple model of a thick $\mathrm{S} 2$ layer enclosed by much thinner S1 and S3 layers with microfibrils on average perpendicular to those in the S2 layer with some cross-banding.

\section{2}

\section{The S2 layer and microfibril fine structure}

The transverse fibril/matrix structure of the wide S2 layer forming approximately 80 to 90 percent of the thickness of the double-wall of two adjacent softwood cells has not always been described consistently. Several authors postulate an S2 structure consisting of thin, approximately round concentric lamellae of helically winding fibrils with inclinations ranging from about 5 to $30^{\circ}$ (Braun, 1992; Côté, 1968; Liese, 1970; Ruel et al., 1978; Scallan, 1974; Stone et al., 1971; Wardrop, 1954), see Fig. 1. Kerr and Goring (1975) proposed an interrupted order of tangential fibril layers according to their observations on potassium permanganate - stained spruce wood. Other authors do not mention a specific arrangement of the $S 2$ fibrils in the direction perpendicular to the cell axis with the exception of "transition" lamellae between the S2 and the adjacent layers S1 and S3 (eg. Core et al., 1979; Fujita and Harada, 1991). Chafe (1974) suggested that the $S 2$ lamellation seen on light and electron micrographs are more likely artefacts and that the S2 appears to be a single thick lamella by its own. Revol et al. (1982) by diffraction measurements

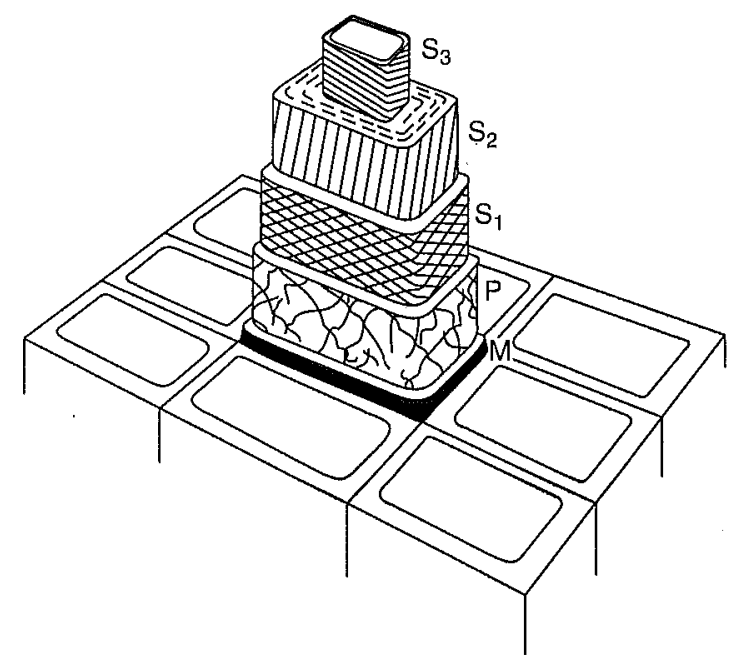

Fig. 1. Schematic diagram of the cell wall according to Bailey (1938), Côté (1968), Liese (1970), and Harada and Côté (1985). In the S2 layer the microfibrils are laid down in a laminar circumferential or concentric pattern 
found a rather random orientation of the S2 fibrils perpendicular to the cell axis. Some radial structures have also been reported. Radial lignin orientations of the $S 2$ have recently been described for softwood compression wood (Singh, 1996). In addition, Chafe (1977) found radial striations of the S2 fibrils of Eucalyptus wood of a tree under severe growing stresses.

According to Abe et al. (1991) the S2 layer consists of closely packed microfibrils at an angle between $0^{\circ}$ and $20^{\circ}$ in a Z-helix. According to Donaldson (1992) the microfibril angle in the S2 layer of radiata pine outerwood at breast height ranges from 10 to $25^{\circ}$ with an average of approximately $20^{\circ}$ in a $Z$-helix.

\section{3}

Recent observations of further fine structure in the $\mathbf{S 2}$ layer

Recently one of the authors and his co-worker reported observations on the transverse fracture surfaces of axially tension-loaded normal softwood specimens (i.e. not compression wood) by means of a high-resolution FE-SEM (field-emission cathode). This study revealed radial or approximately radial (related to the long cell axis) orientations of the transverse structure of the S2 layer which do not fit the present model of concentric fibril lamellae mentioned above, Fig. 2 (Sell and Zimmermann, 1993 a and b; Sell, 1994a, Zimmermann and Sell, 1997).

However, there is considerable evidence that:

- the packing density and the bonds between the distinguishable S2 fibrils (with diameters between 10 to $100 \mathrm{~nm}$ ) are stronger in the radial than in the tangential direction.

- the fibrils of the S2 are oriented (or agglomerated) radially to the cell axis. The tangential thickness of these agglomerations is 0.1 to $1.0 \mu \mathrm{m}$. Radially, they often extend from the $S 1$ to the $S 3$.

- the bonds between the S2 fibrils or of its radial agglomerations, respectively, to the adjacent S1 and S3 layers seem to be stronger than between the S1 layer and the CML, according to the fracture surfaces observed.

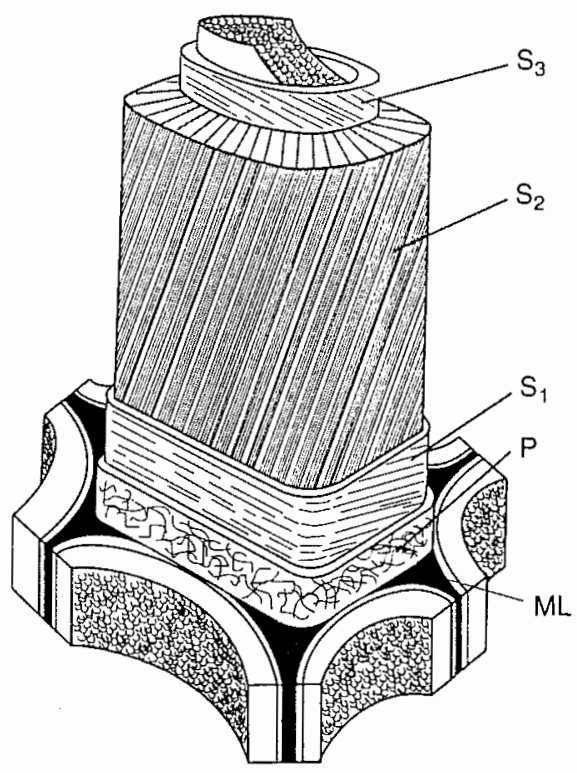

Fig. 2. Schematic diagram of cell wall structure according to Sell and Zimmermann (1993b). The $S_{2}$ layer consists of radially oriented agglomerations of microfibrils separated by more or less radial layers of matrix material
The radial orientation of fibril agglomerations of the S2 layer of softwood tracheids has meanwhile been confirmed by the light microscope (Sell, 1994b). This radial orientation was also found in fibre cells of hardwoods very recently (Zimmermann and Sell, 1997). It needs, however, further confirmations by other independent methods. In this connection it is quite interesting that electron micrographs of the lignin "skeleton" of transverse sections of the coniferous cell wall from which cellulose has been removed chemically by hydro-fluoric acid exhibit evident radial structures of the S2 layer (e.g. see Fig. 13 of Core et al., 1979; Parham and Côté, 1971) which have not been mentioned by these authors, however. Further confirmation of the radial orientation of the cellulosic fibrils and the lignin of the S2 layer has been obtained recently by the selective decomposition of cellulose or lignin by fungi Larsen et al., 1995; Schwarze and Engels, 1997).

A modified model of the entire cell wall of softwoods has been proposed which includes the recent findings of radial fibril orientations of the S2 of softwood tracheids (Sell and Zimmermann, 1993b), as shown in Fig. 2. In conclusion, the structure of the double cell wall might be described as a sandwich consisting of the S2 as thick core layers whereas the CML and its adjacent S1 layers are acting as connecting parts and the $\mathrm{S} 3$ layers as crossbanding faces. Advantages of such a mechanical structure will be discussed below.

\section{3}

\section{Engineering requirements of tree structure}

Trees grow tall to intercept the sunlight required for photosynthesis before other plants such as grasses and shrubs can intercept it. This strategy carries several disadvantages with it:

- the trunk has to support a large weight of biomass and water

- the tree must translocate water/sap a long distance against gravity

- the structure is exposed to strong winds and could be damaged by vibrations

This imposes a number of engineering requirements on the structure of trees, of which only those relevant to this discussion are listed below. The tree must:

1. prevent cell collapse under the large water tensions required for sap movement

2. have sufficient bending stiffness

3. resist crack propagation

4. be able to carry the crown's weight on the stem, as well as resist the forces generated by wind

5. have an efficient vibration damping mechanism

According to Mattheck (1991) natural selection has ensured that tree structure and wood structure at the cellular level are optimised to satisfy the engineering requirements. The work to be described will show that wood at the nanostructural level is similarly optimised.

\section{4}

\section{Effect of microfibril orientation on tree function} and wood properties

4.1

Engineering model of the cell wall

Until now the familiar biological model of wood structure has been used in which the S1 layer adjacent to the compound middle lamella forms the outside of the cell and 
the S3 layer the interior. When it comes to an analysis of the mechanical behaviour of wood, the engineering model proposed by Barber and Meylan (1964) is much more useful. In this model there are no single cells, only double cell walls that can carry loads. The lumens are non-load carrying empty volumes. A cross-section of a double cell wall is shown in Figure 3. It consists of a sandwich structure consisting of the following layers: S3, S2, SI, $\mathrm{CML}, \mathrm{S} 1, \mathrm{~S} 2$, and S3. In the engineering model the very thin S3 layer lies on the outside of the double cell walls, while in the biological model the S3 layer lines the inside of the cell.

\section{2}

\section{Function of the $\mathbf{S 2}$ layer}

\subsection{1}

\section{Strength and stiffness in the axial direction}

The S2 layer is reinforced by microfibrils that usually lie from 5 to 30 degrees to the axis, and it is about forty times thicker than any of the other layers. Quite clearly this layer is very important in supporting the weight of the tree. It has been shown by Cave that both the strength and stiffness (Young's modulus) of wood are very dependent on the microfibrillar angle (Cave, 1968, 1969, 1978; Cave and Walker 1994). The most efficient weight carrying structure with the greatest axial modulus and strength would be one in which the microfibril orientation was perfectly aligned with the axis. It will next be shown that a tradeoff is involved, and that a microfibril angle of $0^{\circ}$ would make the cells very susceptible to transwall fracture, and would destroy the tree's ability to resist wind damage by dissipation of vibration energy.

\subsection{2}

\section{Axial crack propagation}

Consider the propagation of a crack along the axial direction through the double cell wall layer of Figures 1 or 2. Most of the resistance to crack propagation (fracture) will occur in the S2 layers, as these are the thickest. In a single cell wall a crack would propagate by cutting through the matrix material in the same direction as the microfibrils, as the energy required to cut through microfibrils is much larger than that to cut through the matrix material. The fracture would hence propagate at an angle $\phi$ to the axis, where $\phi$ is the microfibril angle. In the case of a double cell

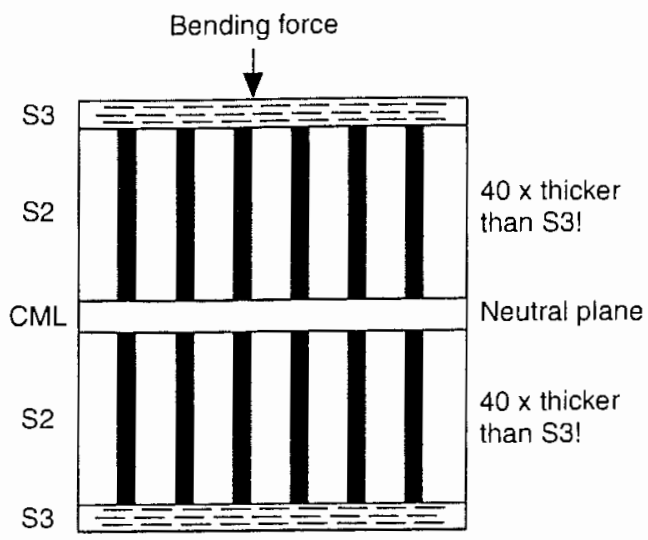

Fig. 3. Cross-section of a double cell wall, showing the direction of bending in the transverse direction. The microfibrils in the $S_{3}$ layer, unlike those in $S_{2}$, lie within the plane, where they increase the bending strength wall with a double S2 layer with microfibril angles of $+\phi$ and $-\phi$ respectively, a fracture can follow two different pathways, and the fracture will follow the path that requires the least fracture energy. The fracture can either propagate in the axial direction and cut alternately through the microfibrils and the matrix material (Fig. 4) or it can follow the microfibril direction in each S2 layer (Fig. 5), which means that the crack front separates into separate cracks in each S2 layer, connected by a fracture surface through the middle lamella region of the double cell wall. This very rapidly reaches the corners of the cell, so that this type of transwall fracture will change rapidly into intrawall fracture.

\subsection{3}

The effect of microfibril angle on transwall and intrawall fracture

Tangential transwall fracture occurs if the energy required to cut through a given length of cell wall in the direction of the cell axis is less than that required to propagate a crack for the same distance along the CML or S1/S2 boundary. A mathematical relation between transwall and intrawall cracking was derived by Booker (1995) and shows that transwall fracture can only occur when the microfibril angle is less than a maximum value. According to Booker (1995) transwall fracture can only occur when:

$\sin \varphi<\left[\left(\frac{a+0.5 b}{t}\right) \times\left(\frac{F}{n E}\right)\right]$

where:

$\varphi=$ microfibril angle

$a=$ tangential cell diameter

$b=$ radial cell diameter

$t=$ double cell wall thickness

$F=$ the smaller of the energies required to split $1 \mathrm{~m}^{2}$ of CML or S1/S2 surface

$n E=$ the energy required to cut through the microfibrils in $1 \mathrm{~m}^{2}$ of $\mathrm{S} 2$ layer oriented perpendicular to the microfibril direction

If some reasonable values are substituted such as $a=b=40 \mu \mathrm{m}, t=4 \mu \mathrm{m}$, and the assumption is made that in the case of most efficient biomass distribution

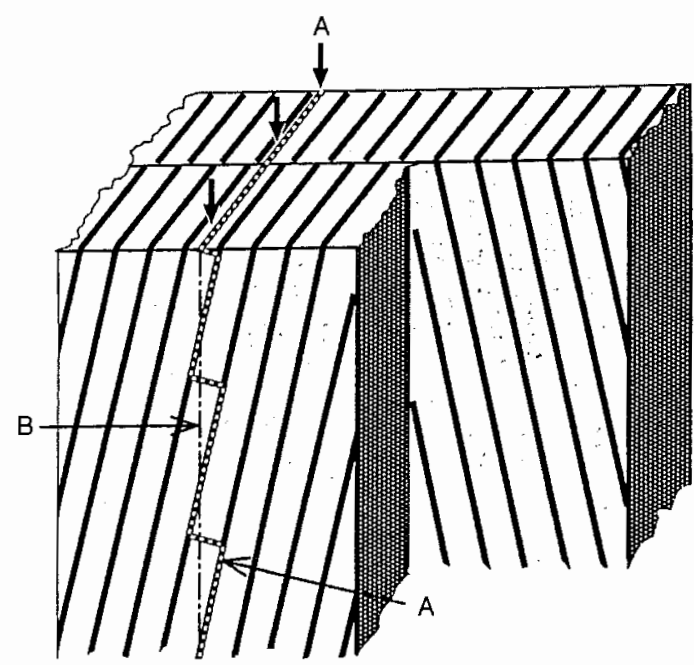

Fig. 4. Transwall fracture propagating through a double cell wall along the axial direction, cutting through microfibril agglomerations (shown in grey) in the process. A: fracture pathway, B: axial direction 


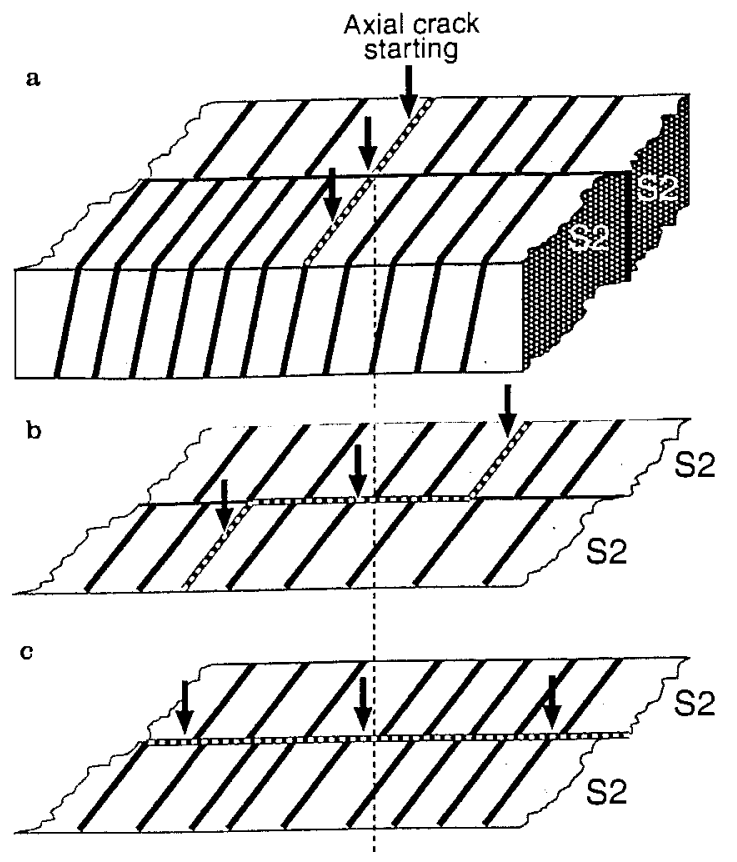

Fig. 5a-c. Conversion of transwall fracture into intrawall fracture a Start of the crack through the matrix material, b Transverse section of the wall lower down, showing how the cracks in $S_{2}$ have propagated along, the microfibril direction through the matrix and opened a crack through the CML. c Transverse section of the wall still further down, where the crack is now confined to the CML

transwall and intrawall failure are equally probable at an average microfibril angle of 20 degrees, it follows that the ratio of the energy required to cut through unit area of cell wall perpendicular to the microfibril direction divided by the energy to cut through unit area of matrix material (i.e. $n E / F)$ is of the order of 40 .

The above formula shows that when the wall thickness increases, transwall fracture will become less probable unless the mean microfibril angle decreases at the same time. In latewood the microfibril angle is smaller than in earlywood, so that the elastic modulus and strength of the latewood in the axial direction is not only greater because of its greater wall thickness and hence density, but also because of the decrease in microfibrillar angle (Mark, 1967). Yet this is achieved without increasing the propensity to transwall checking.

\subsection{4}

\section{Energy absorption mechanism in the tree}

A further reason why a microfibril angle in S2 that is greater than zero is advantageous to the tree is that it provides a vibration damping mechanism at the cellular level that prevents damage to the tree. When a tree sways in the wind, one side of the stem is compressed and the other side is in tension. On the compression side each double cell wall experiences a compression force. Because the microfibrils in the S2 layer of each cell lie at an angle to the axis, under compression each cell will rotate slightly (Fig. 6). Adjacent cells have similar microfibril angles, but the layers in the double cell wall have opposite microfibril orientations, so that the two halves of the cell wall rotate in the opposite direction by an equal amount (Fig. 7). This places the compound middle lamella layer between them in shear. When the tree sways the other way, each half of the double cell wall layer will now rotate in the opposite direction, but again the two halves are rotating in opposite

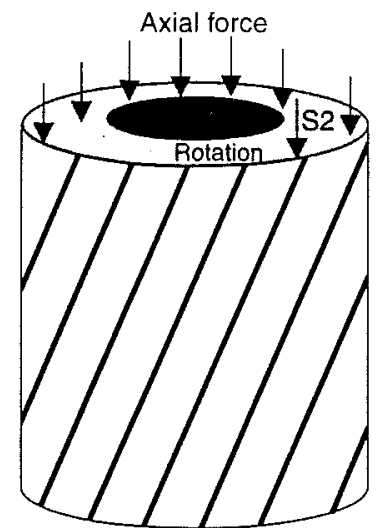

Fig. 6. Compression of the $S_{2}$ layer of the anisotropic single cell wall results in rotation and an increase in diameter

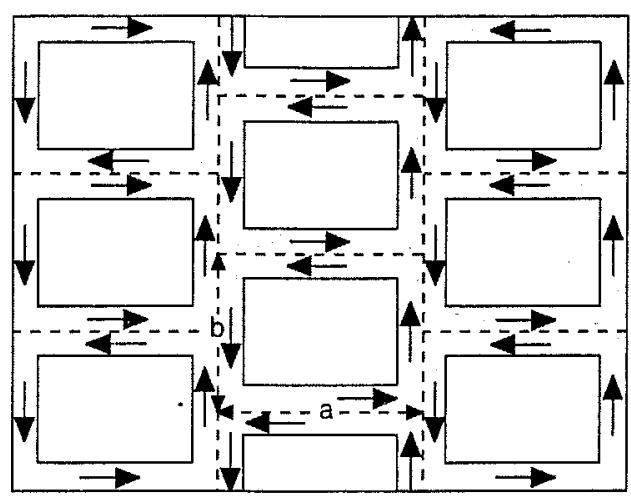

Fig. 7. Transverse view of a number of cells rotating in the same direction (anti-clockwise). The two halves of each double cell wall rotate in opposite directions, placing the middle lamella in shear

directions, so that the CML region will again be sheared. The strongly lignified middle lamella region, like rubber, consists of three-dimensionally connected chain molecules that can move with respect to each other when a shear stress is applied. This dissipates vibrational energy. In the engineering profession polymers in shear (usually rubber) are frequently used for vibration absorption purposes. In other words, the CML has the function in the tree of a vibration absorber at the cellular level.

Further vibration absorption is introduced by the cellulose rib-like structures in the S2 layer of each individual cell. As shown in Figure 6 cyclical rotation of the cell places the radial lignin layers between the cellulose rib-like structures in cyclical shear. This causes vibration damping in this lignin in the same way as it occurs the middle lamella.

\section{3}

\section{Function of the S1 layer}

\subsection{1}

\section{Limitation of excessive cell expansion} under longitudinal compression

When the S2 layer of a cell experiences a compression force, the presence of the microfibrils causes the cell to rotate (Fig. 6). An increase in cell diameter is associated with this rotation. The S1 layer is concentric with the S2 layer and encloses it like a sleeve. According to Abe et al. (1991) the microfibrils in the S1 layer change in orientation from one side to the other from $45^{\circ}$ in an $S$ 
helix through $90^{\circ}$ to about $45^{\circ}$ on the other side. The microfibrils of the outside and inside layers of $\$ 1$ are essentially perpendicular, while most lie more or less perpendicular to the cell axis. In other words, the microfibrils have practically the same orientation as the reinforcing mesh in a plastic garden hose. Just as this mesh limits the increase in diameter of the hose, the reinforcing in the $\mathrm{S1}$ layer prevents excessive radial expansion of the $\$ 2$ layer under compression. As radial expansion and rotation of the S2 layer are coupled, this also limits the maximum rotation of the secondary wall that can occur, which in turn limits the maximum shear stress in the CML and in the matrix material between the radial microfibril agglomerations in the S2 layer. However, as the microfibrils in S1 are not tightly packed (Abe et al., 1991) the S1 layer surrounds the S2 like a loose sleeve, so that the above mechanism probably does not come into play until the increase in cell diameter reaches a given limit. This means that the sleeve effect would only cut in when deformation becomes so large that it threatens to fracture the S2 layer.

\subsection{2}

Effect of $\mathrm{S1}$ microfibril direction on transwall fracture Intrawall fracture does not occur by fracture through the $\mathrm{CML}$, but by fracture along the CML/S1 boundary or the S1/S2 boundary (Donaldson, 1996). An S1 layer with a microfibril angle of $90^{\circ}$ would be just as effective in acting as a protective sleeve than one in which the outer and inner layers are at right angles to each other. However, the latter structure will also resist crack propagation, so that its structure will also help to prevent the transformation of intrawall fracture along the CML/S1 boundary into transwall fracture.

\section{4}

\section{Function of the $\$ 3$ layer}

\subsection{1}

\section{Collapse resistance}

In trees, water moves from the roots to the leaves or needles in continuous water columns under the action of a water tension gradient. This is the Dixon-Joly theory of transpiration (Meidner and Sheriff, 1976). The water tension gradient not only has to overcome the capillary tension of the soil water and the resistance to flow, but it also has to move the water against gravity. In the sapwood tracheids of conifers the lumens are water-filled and conduct the sap. The tension in the water is usually of the order of 0.3 to $0.5 \mathrm{MPa}$ and can reach a maximum of about $2 \mathrm{MPa}$ before stomatal closure occurs. The cell walls have to be able to withstand collapse under these hydrostatic tension forces that act perpendicular to the cell walls of the sapwood as shown in Figure 8. The water tension causes a compression force to act on the cell walls (Booker 1993), which reduces cell volume reversibly, as demonstrated for instance by the diurnal variation in the length of a dendrometer under varying water stress. Considering two adjacent cells, if one is water-filled and the other air or vapour-filled, the transverse forces on the double wall between them are no longer equal and opposite. The transverse force on the cell wall tends to push the cell wall into the lumen, causing cell collapse.

Figure 3 shows the structure of the double cell wall. The CML layer in the centre of the double wall lies at the neutral plane of bending, and its properties are of no

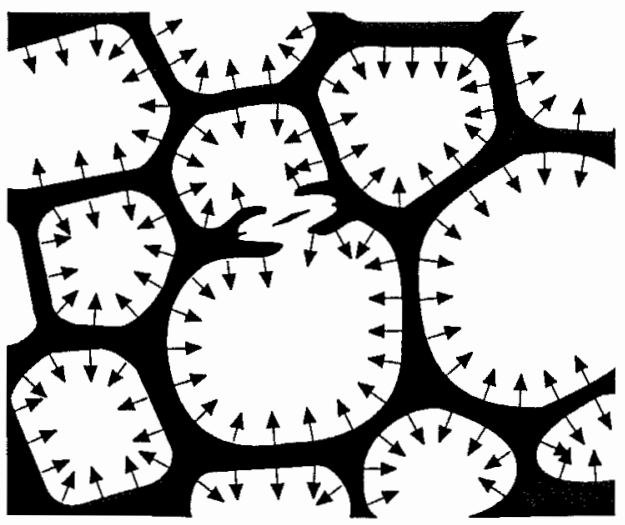

Fig. 8. Hydrostatic tension forces on the cell walls of conifer sapwood

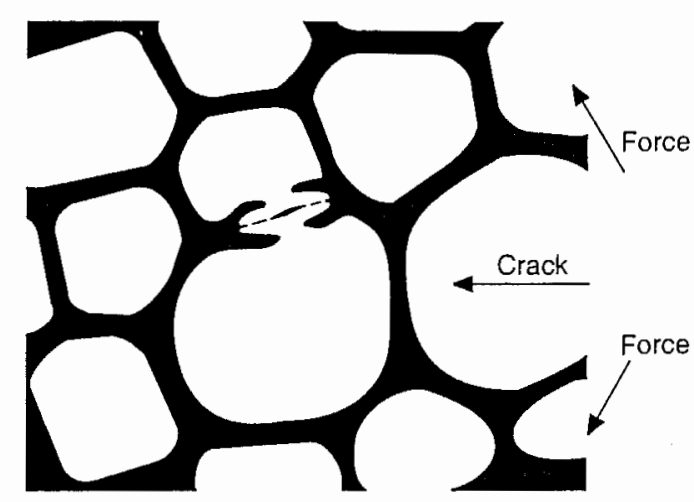

Fig. 9. Direction of the forces acting during the formation of a crack in the transverse direction

importance as far as bending strength is concerned. However, the $S 3$ layers lie at the surfaces of the double cell wall at the position of maximum compressive and tensile stress in the wall. The average microfibril orientation in the S3 layer lies close to the plane of the cell walls along the tangential direction, while that of the S2 layer lies approximately perpendicular to the tangential direction. Hence the microfibrils in the S3 layer are comparatively much more effective in stiffening the wall in the transverse plane than those of the S2 layer. Booker (1993) has calculated that the stiffness of the cell walls to sideways deflection is increased by a factor of about $2 \frac{1}{2}$ by the presence of the S3 cell wall layers acting as cross-banding faces. This makes the cell walls much more capable of withstanding the water tension forces in the xylem cells. On the other hand, it should be borne in mind that it is the total wall thickness that has the greatest effect on collapse resistance.

\subsection{2}

Transwall fracture in the transverse direction

Figure 9 shows the direction of the forces that would act during the propagation of a crack in the transverse direction. The crack first has to penetrate the S3 layer in which most of the reinforcing microfibrils lie almost exactly perpendicular to the direction of the crack. In addition the microfibrils in the outer and inner S3 lie perpendicular to each other. These factors severely restrict the occurrence of transverse checking. In compression wood, where the S3 layer is frequently missing, this often results in checks forming in the unprotected S2 layer. 
Table 1. Functions of the cell wall layers in the living tree

The S3 layer:

Strengthens the cell against collapse (ie. implosion caused by water tension)

Resists transwall fracture in the transverse directions

The S2 layer:

In the stem carries the weight as well as the tension and compression forces generated by the wind

Strongly resists transwall crack propagation in the axial direction

Is part of an energy absorption mechanism at the cellular level with the CML layer that controls wind damage

The S1 layer:

Limits the maximum shear forces in the CML during axial compression, by limiting the maximum diameter increase of the S2 layer

Prevents intrawall cracks from developing into transwall cracks

Combined S3, S2 and S1:

In the Zimmermann and Sell model (1994) the sandwich construction with microfibril-reinforced radial ribs creates extra resistance against buckling and collapse

The CML layer:

Resists delamination of the double cell walls (intrawall checking) and prevents internal checking (Booker 1994)

Forms part of the vibration energy absorption mechanism.

\section{5}

\section{Strength of the combined three layer secondary wall}

According to Sell and Zimmermann (1993 a, b) and Zimmermann and Sell (1997) the microfibrils in S2 are densely packed into rib-like structures that are radially oriented and bonded to the S1 and S2 layers (Fig. 2). Such a structure has several advantages over one in which the microfibrils in S2 are arranged in concentric lamellae (Fig. 1). A single microfibril would have little compression strength because it could easily buckle, although it would be strong in tension. Multiple interconnections between microfibrils greatly increase their buckling resistance under axial compression. The collection of microfibrils in the $S 2$ cell wall layer into rib-like structures that are anchored to the $\mathrm{S} 1$ and $\mathrm{S} 3$ boundaries increases the bending strength of the cells and adds greatly to buckling resistance.

The S1, S2 and S3 layers are strongly bonded together into a sandwich like structure similar to plywood in that the microfibril orientations of the S1 and S3 outer layers are perpendicular to that of the core S2 layer. The sandwichlike structure gives additional strength to the structure:

- collapse resistance against water tension

- buckling resistance against axial compression forces

- bending stiffness against bending forces.

\section{6}

\section{Structures at other levels of organisation that affect strength}

This article is concerned with the relationship between nanostructure and the properties that enhance tree function and survival. For completeness it should be stressed that similar relationships exist at higher levels of organisation. For instance, the tips of tracheids are turned over at an angle of approximately $90^{\circ}$ to the cell axis to reduce fracture forces between cells that could cause the wood to split. Similarly, interlocked grain protects wood from cracking by increasing the surface area and hence the fracture energy of a crack.

\section{5}

\section{Conclusion}

To us, it makes sense to discuss models of the nanostructure of wood not only from the anatomical point of view, but also with respect to the evolutionary optimised mechanical functions for a living tree.
A physical relationship has been shown to exist between transwall and intrawall checking and microfibril angle. The reasons for the microfibrillar angles in the S1, S2 and S3 layers have been elucidated in terms of the mechanical requirements for the successful functioning of trees. These relationships are listed in Table 1 and are extremely important for tree breeding.

For instance, it has recently been suggested by Cave and Walker (1994) that tree breeding could be used to increase the stiffness of the corewood of radiata pine by breeding for trees with a smaller microfibril angle in the corewood. This is a very valuable suggestion as long as it is realised that a tradeoff is involved, and that an excess of zeal in this direction would result in wood that has poor vibration energy absorption and is also very susceptible to transwall checking. Such a tree could be considerably more prone to wind damage. Generalising, it should be clear that singleminded concentration on tree breeding programmes for achieving desirable properties identified by wood technologists, without understanding their relationship to tree growth is likely to lead to poor growth or wind damage. Millions of years of natural selection have eliminated tree designs that are not optimised, and changes to this structure without an understanding of function will lead to serious problems.

\section{References}

Abe H, Ohtani J, Fukuzawa K (1991) FE-SEM observations on the microfibrillar orientation in the secondary wall of tracheids. IAWA bull. n.s.12(4): 431-438

Barber NF, Meylan BA (1964) The anisotropic shrinkage of wood. Holzforschung 18: 146-156

Bailey IW (1938) Cell wall structure of higher plants. Industrial Eng. Chem. 30: 40-47

Booker RE (1993) The importance of the $\mathrm{S}_{3}$ cell wall layer in collapse and wood hardness. Proceedings of the 24th Forest Products Research Conference, 15-18 November 1993, CSIRO Division of Forest Products, Clayton, Victoria, Australia. 3/17, 1-13 Booker RE (1995) The reason for the microfibril orientations in the cell walls of trees. Recent Advances in Wood Anatomy, Eds. L.A. Donaldson, A.P. Singh, B.G. Butterfield, J. Whitehouse. NZ Forest Research Institute Ltd, 273-282

Braun HJ (1992) Bau und Leben der Bäume. (3rd edn). Verlag Rombach, Freiburg

Cave ID (1968) The anisotropic elasticity of the plant cell wall. Wood Sci Technol. 2(4): 268-278

Cave ID (1969) The longitudinal modulus of Pinus radiata. Wood Sci. Technol. 3: 40-48 
Cave ID (1978) Modelling moisture-related mechanical properties of wood. Part 2: Computation of properties of a model of wood and comparison with experimental data. Wood Sci. Techn. 12: 127-139

Cave ID, Walker JCF (1994) Stiffness of wood in fast-grown plantation softwoods: the influence of microfibril angle. For. Prod. Journal, 44(5): 43-48

Chafe SC (1974) On the lamellate structure of the S2 layer. Protoplasma 79: 144-158

Chafe SC (1977) Radial dislocations in the fibre wall of Eucalyptus regnans trees of high growth stress. Wood Sci. Technol. 11: 69-77 Core HA, Coté WA, Day AC (1979) Wood Structure and Identification (2nd edn.), Syracuse University Press, Syracuse, N.Y. Côté WA (1968) The structure of wood and the wood cell wall. In: Kollmann, F.F.R., Côté, W.A. Principles of Wood Science and Technology. Vol 1: Solid Wood. Springer-Verlag, New York Donaldson L (1992) Within- and between-tree variation in microfibril angle in Pinus radiata. NZ J. For. Sci. 22: 77-86 Donaldson L (1996) Clonal variation in the fracture properties of radiata pine wood. Recent Advances in Wood Anatomy, Eds. L.A. Donaldson, A.P. Singh, B.G. Butterfield, J. Whitehouse. NZ Forest Research Institute Ltd, 283-291

Fujita M, Harada H (1991) Ultrastructure and Formation of Wood. In: Hon, D.N.S., Shiraishi N. (Ed.). Wood and Cellulosic Chemistry. Marcel Dekker Inc. New York and Basel

Kerr AJ, Goring DAI (1975) The ultrastructural arrangement of the wood cell wall. Cellul. Chem. Technol. 9, 563-573

Harada HY, Côté WA (1985) Structure of Wood. In: Biosynthesis and biodegradation of wood components (ed. T. Higuchi): 1-42. Acad. Press, Orlando

Larsen UJ, Winandy JE, Green F (1995) A proposed model of the tracheid cell wall of Southern yellow pine having an inherent radial structure in the $S_{2}$ layer. Mater. \& Organismen 29(3): 197209

Liese W (1970) Elektronenmikroskopie des Holzes. In: Freund, H. Handbuch der Mikroskopie in der Technik. Vol 1, Part 1. Umschau-Verlag, Frankfurt a.M.

Mark RE (1967) Cell wall mechanics of tracheids. Yale University Press, New Haven

Mattheck C (1991) Trees, the mechanical design. Springer Verlag, Berlin

Meidner H, Sheriff DW (1976) Water and Plants. Tertiary biology series, Blackie, London
Parham RA, Coté WA (1971) Distribution of lignin in normal and compression wood of Pinus taeda L. Wood Sci. Technol. 5: 49-62 Revol JF, Gancet C, Goring DAI (1982) Orientation of cellulose crystallisation in the $S_{2}$ layer of spruce and birch wood cells. Wood Sci. 14(3): 120-126

Ruel K, Barnoud F, Goring DAI (1978) Lamellation in the S2 layer of softwood tracheids as demonstrated by scanning transmission electron microscopy. Wood Sci. Technol. 12: 287-291 Scallan AM (1974) The structure of the cell wall of wood - a consequence of anisotropic inter-microfibrillar bonding? Wood Sci. 6: $266-271$

Schwarze FWMR, Engels J (1997) Cavity formation and the exposure of peculiar structures in the secondary wall $\left(S_{2}\right)$ of tracheids and fibres by wood degrading basidiomycetes.

Holzforschung. (In press)

Sell J (1994a) Mechanical aspects of new SEM observations on the fibril/matrix structure of the $S_{2}$ layer of softwood tracheids.

Proceedings Congress "Plant Biomechanics", Montpellier,

France. September 1994, pp 163-164

Sell J (1994b) Confirmation of a sandwich-like model of the cel wall of softwoods by light microscope. Holz Roh-Werkstoff 57: 234

Sell J, Zimmermann T (1993a) The structure of the cell wall layer S2-field-emission SEM studies on transverse-fracture surfaces of the wood of spruce and white fir. Forsch. u. Arbeitsberichte EMPA - Abt. Holz, No. 115/28. (German with English Abstract) Sell J, Zimmermann T (1993b) Radial fibril agglomerations of the $S_{2}$ on transverse fracture surfaces of tracheids of tension-loaded spruce and white fir. Holz Roh-Werkstoff 51: 384

Singh A (1996) Ultrastructural features of compression wood cells in relation to bacterial decay in Pinus radiata. Recent Advances in Wood Anatomy, Eds. L.A. Donaldson, A.P. Singh, B.G. Butterfield, J. Whitehouse. NZ Forest Research Institute Ltd, 400407

Stone JE, Scallan AM, Ahlgren PAV (1971) The ultrastructural distribution of lignin in tracheid cell walls. Tappi 54: 1527-1530 Wardrop $A B$ (1954) The fine structure of the conifer tracheid.

Holzforschung 8: 12-29

Zimmermann T, Sell J (1997) The fine structure of the cell wall on transverse fracture surfaces of longitudinally tension-loaded hardwoods. Research \& Work Reports, EMPA-Dept Wood, No. $115 / 35,32 \mathrm{P}$ 